\title{
SUJEITOS, IDENTIDADES E OUTRA(S) AMAZÔNIA(S) NAS LETRAS DAS CANÇÕES DE NILSON CHAVES
}

\author{
Jairo de Araujo Souza ${ }^{1}$
}

\section{RESUMO:}

A proposta deste artigo é discutir outras leituras, saberes e valores sobre a Amazônia, seus sujeitos e suas identidades a partir de algumas letras de canções do compositor paraense Nilson Chaves, abrindo um diálogo com os discursos construídos e instituídos historicamente sobre o território amazônico e como esses elementos se apresentam no trabalho do compositor paraense, que faz uso de uma linguagem que nos permite explorar a temática, deslocando nosso(s) olhar(es) para refletirmos de forma crítica, a Amazônia nomeada e narrada pela história oficial e por discursos hegemônicos e totalizantes ancorados na Modernidade. Fazem parte da discussão aqui proposta, temas recorrentes na produção musical desse compositor, como cultura, arte, política e o Imaginário Social com saberes e valores que ora "desconcertam" e ora "atestam" a lógica do discurso colonial, do cientificismo e do "saber universal".

PALAVRAS-CHAVE:

Música. Cultura. Discursos. Imaginário. Amazônia.

\section{PEOPLES, IDENTITIES AND OTHER AMAZONIAS IN THE SONG LYRICS OF NILSON CHAVES}

\begin{abstract}
:
The aim of this article is to discuss other views, values and knowledge about the Amazon, their peoples and identities from the song lyrics of the composer Nilson Chaves in order to link it to the narratives built historically about the amazonian territories. Also, we seek to discuss how these elements are present in the work of this songwriter who makes use of a language which allows us to approach these issues, shifting our views to a critical reflection over an Amazon nominated and narrated by the official history and hegemonic discourse anchored to Modernity. As part of the discussion here proposed, current themes from this author's musical production like art, politics and the social imaginary with values and knowledge which eventually "assume" or "deny" the logic of a colonial discourse, a scientism and of a "universal knowledge".
\end{abstract}

\section{KEYWORDS:}

Music. Culture. Discourse. Imaginary. Amazon.

O visível, por ser visto, passa a existir, é codificado.

Orlandi.

1 Mestre em Letras: Linguagem e Identidade da Universidade Federal do Acre (2016) e professor dessa mesma Instituição Federal de Ensino, lotado no Centro de Educação, Letras e Artes. 
$\prod_{\text {contribuir proposta é }}^{\text {essa para }}$ uma discussão sobre outras possibilidades de leitura sobrea região amazônica, seus saberes, sujeitos e identidades a partir das letras de três canções do compositor paraense Nilson Chaves. Entre os argumentos relevantes para esta proposta, destaca-se que, no trabalho desse compositor, suas letras e canções nos permitem explorar a temática do chamado discurso amazonialista (ALBUQUERQUE, 2016) que em geral vem acompanhado da ideia de música "regional" ou "local", sem muita reflexão do que isso possa significar ou em que ideologia essa se inscreve. Em relação a isso, ressalta Orlandi (1990, p. 16): "o discurso colonial e seu efeito de sentido como uma 'marca de nascença' ou essência, como um lugar, dá acesso à materialidade da ideologia vigente".

A categorização de uma obra ou produção artística como "regional"não apenas orienta, mas também enquadra, define, vincula, encerra e nos impede, com bastante frequência, de (re) conhecer uma Amazônia pouco descrita, contada e cantada para além das fronteiras (re) inventadas pelos contínuos(re) ordenamentos dos espaços e deslocamentos dos sujeitos e povos que já habitavam a região, outros que vieram a habitar e muitos outros que pela Amazônia passam nas diversas diásporas na maioria das vezes desencadeadas pelo "progresso" do "mundo moderno".

Entendemos a construção dos discursos como parte de um processo ideológico que se constitui no campo da interpretação "sobre lugares e sujeitos", neste caso, o espaço territorial amazônida, como parte de um processo histórico e ideológico que nas palavras de Orlandi (1990, p. 37) "sempre visou organizar, disciplinar a memória e reduzila; os discursos 'sobre' como uma das formas cruciais de institucionalização dos sentidos". Nesse sentido, como nos vemos no espaço que ocupamos e no que 
acreditamos que somos está intrinsecamente ligado a uma história, a uma narrativa e a um contexto estabelecido a partir de um dado momento histórico, que serve não como origem, mas como mudança ou ponto de ruptura do que éramos para o que somos. A esse respeito a autora ressalta:

0 europeu nos constrói como seu "outro" mas, ao mesmo tempo, nos apaga. Somos o "outro", mas o outro "excluído" sem semelhança interna. Por sua vez, eles nunca se colocam na posição de serem nosso "outro". Eles são sempre o "centro", dado o discurso das des-cobertas que é um discurso sem reversibilidade. Nós é que os temos como nosso 'outro' absoluto (ORLANDI, 1990, p. 47).

Nosso debate parte de um posicionamento ancorado nas críticas que os pósestruturalistas fazem às concepções essencialistas e ao universo das "certezas" no campo epistemológico. Buscamos deslocar e redirecionar nossos olhares em relação a valores e saberes tradicionalmente ignorados, silenciados e muitas vezes apagados pela lógica da objetividade cientificista, como nos aponta Teves (2002), ao fazer sua crítica ao que a autora chamou de esgotamento do cientificismo, propondo uma reflexão sobre o Imaginário Social como um espaço de conhecimento que é parte das Ciências Humanas e por isso, pertinente de investigação.

Durante muito tempo, fazer ciência significou poder quantificar os dados da realidade, garantir a generalidade e a objetividade do conhecimento. No afã da universalidade do saber científico, do cognoscível como representação do real, excluía-se o sujeito do conhecimento, sua subjetividade, seus condicionamentos históricosociais (TEVES, 2002, p. 53).

Em grande medida, o discurso cientificista sempre teve como suporte também um olhar colonialista, que se estabeleceu desde os relatos de viajantes à Amazônia em diferentes momentos do período colonial nas Américas, como sugere Linhares (1972, apud SILVA, 2011), que entende os relatos, como fundamentais para o conhecimento que se 
estabeleceu sobre a região:

...são os depoimentos de uma época e da mentalidade de seus homens, reflexos de mitos e fantasias, aspirações satisfeitas e ambições frustradas, revelação de um mundo estranho e desconhecido para onde deveriam convergir as esperanças de enriquecimento de reis e súditos (LINHARES, 1972, p.79, apud SILVA, 2011, p. 79).

Podemos,

assim,

estabelecer uma discussão entre os saberes instituídos a partir de um olhar eurocêntrico na busca por um outro olhar, "descentralizado", isto é, longe das essências ou "origens" e, desse modo,escapar dos paradigmas de "verdade" que se fortaleceram no mundo colonial (e sobrevivem até hoje),especialmente no século XVIII quando se intensifica o valor do saber científico para as monarquias imperiais nas Américas. Estaria presente na letra das canções um contra discurso? Uma fala e uma visão anti-moderna? Ou o autor com sua composição é mero reprodutor de discursos totalizantes? Essas questões norteiam bastante nossa inquietação na ampliação do debate aqui proposto.

As letras das músicas do compositor paraense Nilson Chaves, dentro de nossa proposta de discussão, fazem parte da constituição de memórias e de identidades nas diferentes Amazônias, de imaginários, de diferentes temporalidades, linguagens e vocabulários geralmente (quando) percebidos de forma superficial e enquadrados no âmbito de nomenclaturas ou categorias marginais como "local", "regional", "peculiar" ou, ainda, "exótico". Buscamos, então, ir ao encontro de outros valores e saberes que surgem nas letras de forma recorrente na composição desse autor. Desta forma, acreditamos que as letras das canções Sabor Açaí, Olho de Boto e Olhando Belém, compostas por Nilson Chaves e outros compositores parceiros como Joãozinho Gomes, Cristóvam Araújo, Jamil Damous e Vital Lima, nos darão ao longo do artigo o suporte para a crítica aos discursos 
totalizantes, em especial o discurso do "moderno" e, com isso, sinalizando para a existência e mesmo uma resistência de uma outra leitura acercados sujeitos, lugares, identidades e de suas vivências nas cidades, nas florestas, das cidades nas florestas e das florestas nas cidades.

\section{Quem vai ao Pará parou, tomou açaí ficou}

A Amazônia, durante o século XIX, também não escapou do discurso científico naturalista, de toda uma literatura ancorada no evolucionismo darwinista, do desenvolvimento comercial e industrial nas Américas e dos ideais liberais da sociedade burguesa, que ajudaram a consolidar os valores do progresso, da modernidade e da assim chamada civilização. Neste contexto, os hábitos alimentares dos povos da/na Amazônia, os frutos e outros alimentos sempre estiveram sob a ótica de um discurso colonial eurocêntrico que sempre se impôs, "silenciou" e "apagou" muito das representações e valores de povos indígenas e africanos. Temos até hoje no sincretismo religioso afrocatólico-indígena uma das fortes marcas desse "encontro" histórico de diferentes culturas.

Nesse sentido, o discurso do colonizador europeu, do assim entendido como "branco", "detentor" da cultura "letrada", da linguagem escrita, não tardou em (re) nomear, registrar e classificar os frutos encontrados na região como "exóticos" e, em muitos casos, até suspeitos ou perigosos, impondo assim a sua perspectiva, legitimando o seu olhar como "verdade", já que muitos desses alimentos "periféricos" nem sempre encontravam similares na culinária ou cardápios dos grandes “centros"europeus, particularmente da Europa lusitana.

Destacamos aqui o açaí, que frequentemente despertou impressões das mais variadas nos viajantes, quase sempre marcadas pelo imaginário europeu, como podemos observar na opinião do zoólogo e geógrafo suíço Jean Louis 
Rodolphe Agassiz (1938, apud SILVA, 2011, p. 385), que visitou Belém em 1866, capital da então Província do Pará. Ele informava sua impressão sobre a bebida fruto de uma palmeira da floresta nos seguintes termos: "O gosto é enjoativo, mas dá um prato muito delicado quando se lhe ajunta um pouco de açúcar e farinha d'água". Vale ressaltar que a questão do gosto se trata de um traço cultural dos grupos ou sociedades humanas e não de um dado "natural" ou fisiologicamente determinado. Com efeito, Pierre Bourdieu já nos alertava para o fato de que o chamado "bom gosto" se trata de um traço da cultura burguesa.

Vejamos então a letra da canção Sabor Açaí:

E pra quê tu foi plantado?

E pra quê tu foi plantada?

Pra invadir a nossa mesa

E abastar a nossa casa

Teu destino foi traçado

Pelas mãos da mãe do mato

Mãos prendadas de uma deusa,

Mãos de toque abençoado

És a planta que alimenta

A paixão do nosso povo

Macho e fêmea das touceiras

Onde Oxóssi faz seu posto

A mais magra das palmeiras
Faz mulher do sangue grosso

E homem do sangue vasto,

Tu te entrega até o caroço

E tua fruta vai rolando

Para os nossos alguidares

E se entrega ao sacrifício, Fruta santa, fruta mártir

Tens o dom de seres muito Onde muitos não têm nada Uns te chamam açaizeiro Outros te chamam Jussara

Põe tapioca põe farinha d'água

Põe açúcar não põe nada Ou me bebe como um suco Que eu sou muito mais que um fruto

Sou sabor marajoara, sou sabor marajoara

O açaí, na letra da canção, assume uma posição também de sujeito e não somente de objeto, quebrando assim a lógica objetivista e das dicotomias por esta estabelecida: homem/ natureza e natureza/homem. 0 fruto, que se encontra de forma abundante na região, se revela então como parte de um imaginário sociocultural mais amplo e não se encontra restrito a ser somente um produto ou objeto de consumo, como se pode observar no trecho "que eu sou muito mais que um fruto/ sou sabor marajoara!".

0 açaí se torna literalmente muito mais que um fruto. 
Podemos dizer que Sabor Açaí nos coloca em sintonia com a tessitura de uma outra leitura a partir da realidade vivida pelos diferentes povos (indígenas, pretos, brancos, caboclos e ribeirinhos): "tens o dom de seres muito, onde muitos não têm nada". 0 açaí é muito porque é mais que alimento, esse povo "que não têm nada" encontra no fruto do açaizeiro uma relação histórica e cultural muito forte, uma relação com a terra, nos processos de plantio e colheita, mas também uma relação religiosa mesmo, de uma religiosidade sincrética como vemos nos trechos a seguir: "Macho e fêmea das touceiras / onde Oxóssi faz seu posto". Oxóssi como símbolo da religiosidade afro-brasileira se materializa no fruto, porque Oxóssi é o deus da caça, dos alimentos e é aquele que também garante a fartura e a sobrevivência de seus descendentes na cultura Yorubá, presente na Amazônia desde o Brasil colônia. Logo, o açaí, assim como Oxóssi, representa a força e a vitalidade que homens e mulheres precisam para viver ("Faz mulher do sangue grosso e homem do sangue vasto..."). No trecho "E se entrega ao sacrifício / fruta santa, fruta mártir" novamente a religiosidade aparece como parte desse imaginário, mas desta vez como uma referência a religiosidade cristã, no "sacrifício" do cristo pela humanidade e, por isso, no seu "martírio e santidade". É a fruta que se "sacrifica" para alimentar/salvar a todos.

Todos esses elementos se apresentam simbolicamente na letra da canção como parte de uma narrativa muito mais ampla, diversa e, portanto, numa ruptura com os discursos do "saber universal" que categorizam, hierarquizam os sujeitos e também assim, os reduz. A relação estabelecida com a natureza difere dos parâmetros cientificistas tradicionais, quase sempre geradores e mantenedores do viés amazonialista, que separam sujeitos e objetos na relação natureza/homem, numa lógica de ser humano independente da natureza e que assume este 
processo como algo "natural".

0 que podemos perceber na canção é uma experiência de compartilhamento das vivências nessa região, em que a floresta é muito mais do que mera fornecedora de produtos para o consumo. Analisando o refrão da canção em que se diz: “Põe tapioca põe farinha d'água / põe açúcar não põe nada / ou me bebe como um suco / que eu sou muito mais que um fruto / sou sabor marajoara", inferimos que não há somente uma receita para o consumo do açaí, não há um jeito "correto de apreciá-lo", de bebê-lo ou de comê-lo, o que existem são diferentes formas que se apresentam nas práticas, experiências e encontros de diferentes grupos humanos que habitam a região amazônica e estabelecem diferentes relações com o consumo e a cultura desse fruto, que mesmo tendo sido transformado nas últimas décadas em uma commodity, ainda podemos "relê-lo" dado seu papel histórico e cultural e por isso, plural: o açaí como integrante das práticas sociais e de diferentes (con) vivências. Como exemplo, dessa pluralidade dos saberes que incluem obviamente a linguagem como parte do processo ("uns te chamam açaizeiro, outros te chamam jussara"), o açaí é renomeado como jussara em muitos lugares Brasil afora, em especial, no Maranhão onde é mais comum encontrá-lo com esse nome. Temos, portanto, rupturas com o tempo e a lógica do "moderno" que tudo reduz com a ideia do "original", da "raça", da "origem", do "nativo", etc. Valores que não se sustentam em uma diversidade de saberes e práticas sociais, mas se reconfiguram.

\section{Às margens de outra cidade}

Assim como na letra de Sabor Açaí, na canção Olho de Boto podemos apontar uma trajetória que também desloca nosso olhar e nos convida a fazer outras leituras, a partir dos lugares e sujeitos que compõem as cenas da região. $\mathrm{Na}$ perspectiva da letra de Olho de Boto, há elementos que revelam no próprio "ritmo de vida" amazônida - para fazer uso de um termo que 
nos remete aos contextos da chamada "vida moderna" -, rupturas que trazem à tona outras temporalidades, outras maneiras de lidar com o tempo, modos de viver que desafiam a lógica das metrópoles, como ícones do progresso, da racionalidade e da civilização moderna.

As cidades, lugar onde "tempo é dinheiro", do trabalho fabril, das "novidades" tecnológicas, da mecanização e automação das relações humanas, da pressa e da urgência inventada pela indústria e pelo comércio, não vêem sua lógica contemplada no viver das cidades "cravadas" no meio da floresta e à margem dos rios da região. Nesse cenário de uma contrapartida à Modernidade devido à uma impressão de "instabilidade" da natureza, Euclides da Cunha registrou em sua obra À margem da história:

A impressão dominante que tive, e talvez correspondente a uma verdade positiva, é esta: o homem, ali, é ainda um intruso impertinente. Chegou sem ser esperado nem querido - quando a natureza ainda estava arrumando seu vasto e luxuoso salão. E encontrou uma opulenta desordem... Os mesmos rios ainda não se firmaram nos leitos; parecem tatear uma situação de equilíbrio derivando, divagantes em meandros instáveis, contorcidos em "sacados", cujos istmos e reveses se rompem e se soldam numa desesperadora formação de ilhas e de lagos de seis meses... (CUNHA, 1967, p. 12)

Nos rios da Amazônia, o tempo "moderno" e "exato" do relógio e dos ponteiros passa a ser constantemente, digamos, "desafiado" pelas vazantes e cheias das marés, pelas curvas dos rios e igarapés, pelas travessias de varadouros e dos igapós e por uma geografia que "insiste" em não se "render" ou "moldar-se" em definitivo aos avanços do "mundo moderno" em seus diferentes momentos históricos. A famosa "pontualidade britânica" e tudo que essa ideia representa como símbolo do trabalho e da modernidade entra em choque com saberes, tempos e valores que não se adéquam a sua lógica. Nesse sentido, os sujeitos que habitam esse lugar também 
vão "desobedecer" à ordem do "progresso" e constantemente serão enquadrados como preguiçosos e incompetentes para o trabalho numa cidade moderna, já que também fazem parte dessa natureza "selvagem", "primitiva" e "atrasada" das Américas.

Seguimos com a análise da letra da canção Olho de Boto:

E tu ficaste serena Nas entrelinhas dos sonhos Nos escaninhos do riso Olhando pra nós escondida Com os teus olhos de rio Viestes feito um gaiola Engravidado de redes Aportando nos trapiches Do dia a dia e memória Com os teus sonhos de rio E ficaste defendida Com todas as suas letras Entre cartas e surpresas Recírio, chuva e tristeza Vês o peso da tua falta Nas velas e barcos parados Encalhados na saudade De Val-de-Cans ao Guamá Porto de sal das lembranças Das velhas palhas trançadas $\mathrm{Na}$ rede de um outro riso Às margens de outra cidade Ah, os teus sonhos de rio! Olho de Boto

No fundo dos olhos de toda a paisagem

Talvez a palavra-chave da letra da canção Olho de Boto seja a palavra saudade. A saudade de uma outra Belém do Pará, ou de um outro tempo que quase se apagou pelos processos desencadeados pela lógica do "desenvolvimento", pela vida urbana e por uma relação histórica estabelecida com a região; e que, apesar disso tudo, seus sujeitos e outros seres, nunca se "apagaram" ou desapareceram por completo quando observamos no trecho "Olho de boto / no fundo dos olhos de toda a paisagem". Está lá em toda a "paisagem", por toda a parte. Mas o que está em toda a parte não é apenas o "olho de boto" e sim, a vida que existe nesse lugar, dos povos e outros seres, lugar em que a natureza é indissociável do social, do humano, do místico, do urbano e do "moderno" que se impôs ao longo dos séculos. Pode parecer invisível,"no fundo dos olhos", mas está lá, sempre, "olhando pra nós escondida", como parte dos processos objetivos e subjetivos que compõem a realidade instituída e que se institui, de forma conflituosa nas lutas pela sobrevivência e pelo poder em suas mais variadas instâncias. 
0 imaginário também como instituidor de verdades dá sentido àquilo que nos é verdadeiro: os sentimentos de tristeza, saudade e dor fazem parte desse cenário na letra da canção e apontam para uma outra "via" de percepção de como esses sentimentos compõem a estrutura do que é dado como "realidade".

Olho de Boto nos faz olhar um outro cotidiano, um outro viver e existir, pelas imagens, lugares e sujeitos que compõem o cenário da região.Para além das abordagens metodológicas e do cientificismo, o imaginário social amazônida pode ser analisado também a partir do que nos ressalta Teves (2002), em busca de uma produção de conhecimento que não esteja alheia às práticas sociais, aos estudos do cotidiano, das condições objetivas e subjetivas constituintes dessas relações e ao estabelecimento de um olhar plural e não "universal".

As abordagens compreensivas, como as que remetem ao Imaginário Social, vêm oferecendo aos cientistas e pensadores sociais uma alternativa para o entendimento de processos que regulam a vida em sociedade. Embora sob enfoques diferentes admitem que nos estudos das sociedades modernas tornase necessária a exploração do invisível que existe na realidade social, aquilo que tem força, que impele, mas que se encontra em outras instâncias do saber (TEVES, 2002, p. 62).

A realidade objetiva permanece constatada através da "pobreza" do lugar, dos processos a que são submetidos os sujeitos pelas condições de trabalho na navegação, a lógica do comércio de peixe às margens dos rios; no entanto, não podemos reduzir a realidade e limitá-la aos parâmetros do empírico e do dado "real". A poesia de Olho de Boto nos faz viver a experiência de que a realidade se constitui de uma dualidade objetiva e subjetiva e fora de um paradigma hierarquizante, em que o que é objetivo se sustenta sem o valor da subjetividade, que se caracteriza também pela imaginação e por narrativas que produzem sentidos no campo das crenças, dos ritos, do simbólico e do 
semântico. Justificamos aqui o fato de escrevermos "vivera experiência" e "nos faz olhar" como um contraponto à ideia de que o texto nos "faz pensar" ou "compreender" a realidade, com isso, reiteramos nosso posicionamento e crítica. Em suma, o moderno se reconfigura também como um "outro moderno", pois em Olho de Boto, a cidade na floresta se transforma, o "tempo" dos rios "renegociam" o tempo dos relógios dos ponteiros. Talvez não seja preciso já ter navegado nos rios da Amazônia para "mergulhar" no imaginário da letra da canção. Existe a pressa da modernidade, mas essa se "altera", se "rende" para contemplar outras dinâmicas há muito percebidas por autores como Leandro Tocantins que nos confirma em sua obra, quando diz que o Rio Comanda a Vida.

\section{Um curupira de gravata e sapato}

Abordaremos aqui a identidade apenas como resultado de processos de narrativas, uma imagem tecida, escrita e fixada por um "outro" (ORLANDI, 1990) e compreendemos ser difícil e complexa as tentativas de debater esse tema. Por isso, em nossa proposta nos limitamos a discutir a identidade como um construto (RAJAGOPALAN, 2002), como parte de processos geopolíticos históricos, muitas vezes contraditórios e bastante reducionistas acerca dos sujeitos e suas vivências, mas especificamente no contexto amazônida, um processo que se apresenta vivo na letra de Olhando Belém.

O século XIX nos marcou como um período de forte consolidação da ideia de identidade ou da construção de identidades essencialistas ligadas aos projetos de nação e da geopolítica dos Estados, que compuseram esse período da História. Rajagopalan contribui para a discussão acerca da identidade como representação:

0 que os estudos culturais, notadamente nas mãos de estudiosos como Bhabha, têm enfatizado é que o caráter performativo da constituição de identidades é algo inegável sobretudo a 
partir do final da Segunda Grande Guerra, quando a ordem mundial baseada em concepções historicistas e essencialistas das identidades nacional, étnica, linguística e assim por diante se revelou demasiadamente reducionista e míope (RAJAGOPALAN, 2002, p. 83).

É dentro das limitações e contradições desses processos históricos de lógica objetivista que pretendemos desenvolver nossa discussão sobre identidade na letra da canção Olhando Belém, em que o sujeito e o seu lugar no mundo são entendidos como "periféricos", tendo como referência um centro idealizado aos moldes da ideia do Moderno.

0 sol da manhã rasga o céu da Amazônia

Eu olho Belém da janela do hotel

As aves que passam fazendo uma zona

Mostrando pra mim que a Amazônia sou eu

E tudo é muito lindo

É branco, é negro, é índio

No rio Tietê mora a minha verdade

Sou caipira, sede urbana dos matos

Um caipora que nasceu na cidade

Um curupira de gravata e sapatos
Sem nome e sem dinheiro

Sou mais um brasileiro

Olhando Belém enquanto uma canoa desce o rio

E o curumim assiste da canoa um Boeing riscando o vazio Eu posso acreditar que ainda dá pra gente viver numa boa Os rios da minha aldeia são maiores do que os de Fernando Pessoa

(E o sol da manhã rasga o céu da Amazônia)

Olhando os meus olhos de verde e floresta

Sentindo na pele o que disse o poeta

Eu olho o futuro e pergunto pra insônia

Será que o Brasil nunca viu a Amazônia?

E vou dormir com isso

Será que e tão difícil?

Dessa forma, somos críticos também ao perceber que o compositor não consegue "escapar" de um olhar amazonialista ao identificar aspectos da região dentro dos "padrões" estabelecidos historicamente por um olhar reducionista da Amazônia como um lugar de "pureza" e "beleza", em que seus sujeitos "racialmente" narrados e reduzidos, aparentemente convivem tranquilamente neste lugar, como se lê no trecho "E tudo é muito lindo 
/ É branco, é negro, é índio". Este é um aspecto interessante de se observar, já que dada a complexidade histórica em que nossas subjetividades foram, digamos assim, "forjadas", dificilmente nos encontraremos isentos das contradições de nossos próprios discursos e posicionamentos, assim como o compositor.

Olhando Belém reitera a Amazônia como um lugar onde convivem o "moderno" e o "primitivo", sem se estabelecer a questão como um problema a ser resolvido ("E o curumim assiste da canoa um Boeing riscando o vazio"), mas como parte de uma condição "natural" desta região. A ideia de lugar "isolado" e "distante" passa a ser a "identidade" desse lugar e de seus sujeitos; e sua "beleza" reside, de acordo com esse olhar, nessa "essência" de lugar exótico e distante. Temos aqui, de novo, o olhar do "outro" (ORLANDI, 1990), que aqui chegou e que passa a ser o nosso olhar, o olhar do viajante histórico reiterado, o cenário "moderno" do contato do indígena em sua "simples" embarcação contemplando a aeronave gigante cruzando os céus da região; assim como no passado quando o contato se dava com a chegada das embarcações vindas da Europa. Em outras palavras, identidades tecidas e fixadas pela narrativa histórica e colonial do contato entre os povos.

A Amazônia, desde o século XVI, já era percebida como um "paraíso perdido", como nos relata Euclides da Cunha (1908). O termo "perdido" pode ser compreendido como sinônimo de invisível, como a Amazônia na canção: "Eu olho o futuro e pergunto pra insônia / será que o Brasil nunca viu a Amazônia?". Nunca viu, porque o nosso olhar dado pelo "outro" nos "cegou" e "apagou" aquilo que nunca enxergamos, não importa quão extensa seja a região Amazônica, pois o discurso colonial da(s) essência(s) nos narrou e nos marcou a-historicamente. Talvez, esse argumento responda a pergunta do compositor paraense: "Será que 
é tão difícil?".

No entanto, a discussão não se encerra, mas o questionamento se mantém; seremos capazes de redirecionar nossos olhares, "desconstruir" ou reconfigurar discursos? Acreditamos que esse seja um processo contínuo que se dá através da própria língua que como estrutura participa desses processos dialógicos, ideológicos e discursivos numa trama ou jogo da linguagem (ORLANDI, 1990, p. 52) no qual os participantes de forma conflituosa podem ou não ressignificar seus lugares no plano discursivo e a produção criativa ou artística ganha um espaço/papel importante nesse campo das tramas discursivas que estabelecem sentidos para as rupturas ou manutenção de "verdades".

\section{Considerações finais}

Propomo-nos aqui a discutir, a partir das letras de três canções do compositor paraense Nilson Chaves, questões referentes aos sujeitos e lugares, linguagens e identidades presentes na região Amazônica, fazendo uma crítica ao(s) olhar(es) amazonialista(s) e de discursos que remontam à ideia do que é moderno, ao cientificismo, ao discurso eurocêntrico/ colonialista como parte de nossa história. Acreditamos que um posicionamento inspirado no movimento pósestruturalista pode contribuir para uma mudança de perspectiva, sendo a crítica um instrumento que nos permite "dar um passo" em direção à superação de contradições da própria vida moderna, da qual a Amazônia faz parte constitutiva. A Amazônia é um conceito moderno e por isso, não pode ficar de fora (na verdade, nunca esteve) do foco de diversos momentos históricos, em particular, a partir do século XVI com as navegações europeias mundo afora.

Nesse sentido, Berman nos traz uma contribuição para o debate dentro desta perspectiva em busca de outras leituras de/ para o mundo:

Venho tentando demonstrar que a mais severa crítica à vida moderna tem $\mathrm{a}$ 
imperiosa necessidade de recorrer ao modernismo, para nos mostrar em que ponto estamos e a partir de que ponto podemos começar a mudar nossas circunstâncias e a nós mesmos. Em busca de um ponto de partida, retornei a um dos primeiros e grandes modernistas, Karl Marx. Voltei a ele não tanto por suas respostas mas por suas perguntas. 0 que de mais valioso ele nos tem a oferecer, hoje, não é um caminho que nos permita sair das contradições da vida moderna, e sim, um caminho mais profundo e mais seguro que nos coloque exatamente no cerne dessas contradições. Ele sabia que o caminho para além das contradições teria que ser procurado através da modernidade, não fora dela. Ele sabia que precisamos começar do ponto onde estamos: psiquicamente nus, despidos de qualquer halo religioso, estético ou moral, e de véus sentimentais, devolvidos à nossa vontade $\mathrm{e}$ energia individuais, forçados a explorar aos demais e a nós mesmos para sobreviver; e mesmo assim, a despeito de tudo, reunidos pelas mesmas forças que nos separam, vagamente cônscios de tudo que o que poderíamos realizar juntos, prontos a nos distendermos na direção de novas possibilidades humanas, a desenvolver identidades e fronteiras comuns que podem ajudarnos e manter-nos juntos, enquanto o selvagem ar moderno explode em calor e frio através de todos nós" (BERMAN, 1986, p. 125).

Os críticos do pósestruturalismo apontam como falha desse movimento a falta de consistência, sua "negatividade" e a falta de uma proposição mais clara e contundente; chegam a assinalá-la como uma ação política do "desespero". Acreditamos que Berman nos traz a reflexão de que não há desespero algum; e que as perguntas são mais importantes do que as respostas, fazendo talvez uma crítica de que foi justamente a insistente busca por respostas que tenha nos trazido até o ponto onde nos encontramos. Vejamos o que James Williams nos diz acerca de tentar o "novo":

Não há nenhuma contradição em negar a liberdade e ainda assim 'testar algo', porque aqui 'testar' indica uma relativa maleabilidade numa situação, ao invés de um livre-arbítrio absoluto. Não somos totalmente livres para chegar a uma decisão; antes, as muitas influências diferentes sobre um ato permitem $o$ pensamento 
quanto às decisões. Essas decisões são, em si mesmas, influenciadas, mas podemos considerá-las relativamente livres, a ponto de pensá-las como decisões nossas, mas apenas temporariamente e sempre de uma maneira aberta à crítica e a diferentes interpretações criativas" (WILLIAMS, 2013, p. 232).

Propor o "novo" pode ser uma encruzilhada cheia de "armadilhas", já que as propostas se manifestam fazendo uso da linguagem e a linguagem (também como estrutura) éum arcabouço de histórias, vozes e silêncios que nos precedem como resultado de processos históricos de colonização nas Américas, em que "os colonizados não podem ocupar posições discursivas (com seus estatutos e sentidos) que o colonizador ocupa" (ORLANDI, 1990, p. 52), dos quais não temos medida $\mathrm{e}$ clareza de como esses nos afetam, nos orientam e até determinam nossas posições em muitos casos. No entanto, ainda em sintonia com Orlandi, podemos tratar a questão do(s) silêncio(s), de forma que, ao mesmo tempo em que funciona para silenciar ou apagar sentidos, ele pode também funcionar como um elemento de resistência ao fazermos uso dos espaços discursivos "não ditos", "não ocupados" pelo discurso "dominante", o "silenciado" precisa entrar, retomamos aqui, no jogo da linguagem (ORLANDI, 1990) e acrescentamos a esse argumento, a necessidade de enxergarmos a partir de então, uma fusão desses elementos, fusão que já ocorre de forma contínua dentro de nossa leitura e crítica.

Em relação à Amazônia, talvez um dos caminhos resida em tentar "falar a língua desse lugar", ao invés de tentar compreendê-lo. Talvez precisássemos esquecê-la como espaço onde o moderno não "chegou" ou não se "completou" e sim, percebermos que ele, o "moderno", já chegou há bastante tempo; e é parte constitutiva deste espaço territorial, é parte de uma estética criativa onde se (re)configuram cotidianamente e de maneiras conflitantes, os discursos, saberes e valores 
e que não vão encontrar nenhuma representatividade nas dicotomias de um conhecimento estruturalista e tradicional; como por exemplo, nas dicotomias moderno $\mathrm{x}$ primitivo $\mathrm{e}$ desenvolvido $\mathrm{x}$ atrasado. Numa perspectiva pós-estruturalista, inspirado nas ideias de Jean François Lyotard, que considera uma filosofia da estética e dos eventos, James Williams assinala:

Um evento não é algo que acontece a alguém, compreendido, por exemplo, como ver algo acontecer de uma maneira imparcial: A vê B. Ao contrário, um evento é uma transformação em coisas inseparáveis, no sentido em que elas aparecem de um modo novo com o evento: (A) e (B) se tornam $\left(A^{\prime} B^{\prime}\right)$ ... Não é uma conexão entre duas coisas, mas uma fusão delas numa transformação contínua (WILLIAMS, 2013, p. 121).

Finalmente, quando falamos de Amazônias no plural, assim como linguagens e identidades buscamos nos aproximar de processos contínuos de transformação e significância. Isto para o nosso debate seria uma proposta de "desconstrução", não para o desaparecimento da estrutura (linguagem e discurso), que consideramos impossível, mas para apreendermos esses elementos como parte da objetividade e da subjetividade imbricados, não mais duais ou separados; mas dentro de uma somatória de criações que não se fecha nas estruturas que insistem em representar a realidade independentemente dela. Acreditamos ser importante perceber as constantes transformações no cotidiano que pode ser e é diariamente reinventado sem cessar e dentro de outras perspectivas de um moderno nunca antes experimentado. $\mathrm{Ou}$ ainda, de um novo iluminismo como propõem os pósestruturalistas a partir de uma outra estética que perceba a arte e a criação como eventos transformadores.

\section{Referências}

ALBUQUERQUE, G. R. Amazonialismo, In: ALBUQUERQUE, G. R.; SARRAFPACHECO, A. (Orgs.). Uwa'kürü Dicionário Analítico. Rio Branco (AC): Nepan Editora, 2016, pp. 7396. 
BERMAN, M. Tudo que é sólido desmancha no ar. $A$ aventura da modernidade.Tradução de Carlos Felipe Moisés e Ana Maria L. Ioratti. São Paulo: Companhia das Letras, 1986.

CHAVES, N. Tempo Destino. 25 Anos Ao Vivo.Outros Brasis gravadora, 1999. Compact Disc (CD), 69min.

CUNHA, E. À margem da história. Cidade do Porto: Editora Lello, 1967.

ORLANDI, E. P. Terra à vista. Discurso do confronto: velho e novo mundo. São Paulo/Campinas: Cortez/Editora da Universidade Estadual de Campinas, 1990.

RAJAGOPALAN, K. A construção de identidades e a política de representação, In: FERREIRA, L. M. A.; ORRICO, E. G. D. (Orgs). Linguagem, identidade $e$ memória social: novas fronteiras, novas articulações. Rio de Janeiro:
DP\&A, 2002, pp. 77-88.

SILVA, F. H. T. Aos nossos olhos europeus: alimentação dos paraenses nas crônicas de viajantes europeus. Programa de Pós-Graduação em História Social da Pontifícia Universidade Católica de São Paulo/ PUC-SP, 2011.

TEVES, N. Imaginário Social, Identidade e Memória. In: FERREIRA, L. M. A.; ORRICO, Evelyn G. D. (Orgs). Linguagem, identidade e memória social: novas fronteiras, novas articulações. Rio de Janeiro: DP\&A, 2002, pp. 53-68.

WILLIAMS, J. Pós-Estruturalismo. Tradução de Caio Liudvik. 2. ed., Petrópolis (RJ): Vozes, 2013 (Série Pensamento Moderno).

Data de recebimento 23/09/2016 Data de aceite 7/3/2017 